\title{
Long-Term Treatment of Postmenopausal Osteoporosis
}

\author{
Jacques P. Brown \\ Division of Rheumatology, Department of Medicine, Laval University, Quebec City, QC, Canada
}

Osteoporosis is an incurable chronic condition, like heart disease, diabetes, or hypertension. A large gap currently exists in the primary prevention of fractures, and studies show that an estimated $80 \%$ to $90 \%$ of adults do not receive appropriate osteoporosis management even in the secondary prevention setting. Case finding strategies have been developed and effective pharmacological interventions are available. This publication addresses how best to use the pharmacological options available for postmenopausal osteoporosis to provide lifelong fracture protection in patients at high and very high risk of fracture. The benefit of osteoporosis therapies far outweighs the rare risks.

Keywords: Osteoporosis, postmenopausal; Diphosphonates; Denosumab; Duration of therapy

\section{INTRODUCTION}

Osteoporosis is a systemic skeletal disease characterized by low bone mineral density (BMD) and deterioration of bone architecture, resulting in reduced bone strength and, consequently, increased susceptibility to fractures [1]. The clinical manifestation of osteoporosis is a fragility fracture, and about $80 \%$ of all fractures are osteoporosis-related [2]. As fractures are associated with a decrease in quality of life and an increase in premature mortality, disability, and financial burden [3-6], it is important to identify individuals at high and very high risk of fracture and to provide them with adequate therapeutic options.

A large gap currently exists in the primary prevention of fracture, and studies show that an estimated $80 \%$ to $90 \%$ of adults do not receive appropriate osteoporosis management even in the

Received: 5 May 2021, Revised: 12 May 2021, Accepted: 17 May 2021

Corresponding author: Jacques P. Brown

Division of Rheumatology, Department of Medicine, CHU de Quebec Research Centre, 2705 Boulevard Laurier, Bureau TR-83, Quebec City, QC G1V 4G2, Canada

Tel: +1-418-650-2661, Fax: +1-418-650-6574,

E-mail: jacques.brown@crchudequebec.ulaval.ca

This work was presented orally at the luncheon symposium on October 30, 2020 during the 17th Asia-Oceania Congress of Endocrinology and the 8th Seoul International Congress of Endocrinology and Metabolism (AOCE-SICEM 2020). secondary prevention setting [2,7]. In contrast, approximately $90 \%$ of patients with cardiovascular disease are provided appropriate secondary preventive care [8]. System-level and countrylevel healthcare initiatives have been implemented worldwide to focus on addressing the secondary fracture prevention gap $[9,10]$, with several reports showing these initiatives being effective in reducing not only subsequent fragility fracture rates, but also associated mortality [11-13]. Considering these data and the current fracture prevention gap, it is important to further improve knowledge on the optimal osteoporosis treatment regimen in the secondary prevention setting [14].

This publication addresses how best to use the pharmacological options available for postmenopausal osteoporosis to provide lifelong fracture protection in patients at high and very high risk of fracture. Managing patients with moderate fracture

\footnotetext{
Copyright $\odot 2021$ Korean Endocrine Society

This is an Open Access article distributed under the terms of the Creative Commons Attribution Non-Commercial License (https://creativecommons.org/ licenses/by-nc/4.0/) which permits unrestricted non-commercial use, distribution, and reproduction in any medium, provided the original work is properly cited.
} 
risk and drug holidays will not be addressed.

\section{FRACTURE RISK ASSESSMENT}

\section{Patients at high risk of fracture}

The first step is to identify which patients are at high or very high risk of fracture. Prognostic tools, among which the Fracture Risk Assessment Tool (FRAX) is the most widely used, are available to identify individuals at high risk of osteoporotic fracture and to assist physicians in management decisions $[15,16]$.

Most osteoporosis guidelines, including the Korean Society for Bone and Mineral Research (KSBMR) recommend treatment for women at high risk of fracture, using fixed intervention thresholds, defined as: (1) postmenopausal women (age 50 and older) with a prior major osteoporotic fracture (MOF; hip, clinical vertebral, humerus, forearm) without the requirement of an osteoporotic BMD (lumbar spine or hip T-score $\leq-2.5$ ); (2) women $\geq 65$ years or younger with risk factors and an osteoporotic BMD [17]. Under this guideline, patients receive coverage for medical treatment costs over a period of 3 years [17].

In the UK, the National Osteoporosis Guideline Group (NOGG) adopted an age-dependent threshold up to the age of 70 years with a fixed threshold thereafter. These lower intervention thresholds (LIT) were set at a risk (FRAX 10-year probability of MOF) equivalent to that of a postmenopausal woman of average body mass index with a prior fragility fracture, no additional risk factors, and without knowledge of BMD [18,19].

\section{Patients at very high risk of fracture}

Some authors [20-22] have suggested improving the predictive ability of FRAX for patients at very high risk of fracture by integrating characteristics of prior fractures (number, location, and time since prior fracture). Because the number, location, and time since prior fracture are associated with an increased risk of future fracture [23], upward adjustments of fracture risk in individuals with multiple fractures, MOF, or recent prior fractures (within 2 years) improve FRAX calibration in the small subgroup (approximately 10\%) of individuals at very high risk while maintaining the 10-year probability as the best model $[24,25]$. NOGG has recently proposed an upper intervention threshold of 1.6 times the pre-existing intervention threshold (LIT), characterizing $10 \%$ of women aged 50 years or more at very high risk of fracture [26].

In Korea, the Korean fracture risk score is a valid alternative to identify women at very high risk of fracture [27]. In a nationwide cohort design with a large representative population from a validated database, the three most important risk factors for osteoporotic fracture were advanced age, history of recent fragility fracture (within 2 years), and recent use of oral glucocorticoids ( $>30$ days in the last year). The algorithm is available for self-assessment at a web-based calculator (http://www.nhis. or.kr) without BMD measurements.

\section{RECENT TREATMENT RECOMMENDATIONS}

The Endocrine Society has recently published a clinical practice guideline update on Pharmacological Management of Osteoporosis in Postmenopausal Women [28], in which they proposed the following recommendations:

- In postmenopausal women at high risk of fractures, we recommend initial treatment with bisphosphonates (alendronate, risedronate, zoledronic acid, and ibandronate) or denosumab as an alternative initial treatment, to reduce fracture risk.

- In postmenopausal women with osteoporosis at very high risk of fracture, such as those with severe or multiple vertebral fractures, we recommend teriparatide treatment for up to 2 years for the reduction of vertebral and nonvertebral fractures.

- In postmenopausal women with osteoporosis at very high risk of fracture, such as those with severe osteoporosis (i.e., low Tscore $<-2.5$ and fractures) or multiple vertebral fractures, we recommend romosozumab treatment for up to 1 year for the reduction of vertebral, hip, and nonvertebral fractures.

Head-to-head trials have documented the superiority of boneforming agents (teriparatide [TPTD] or romosozumab) over antiresorptives (risedronate or alendronate) for reducing fractures in postmenopausal women at very high risk of fracture $[29,30]$. In these patients, the optimal sequence should be to initiate treatment with a bone-forming agent first followed by an antiresorptive, and not the reverse [31]. TPTD and romosozumab treatment should always be followed by an antiresorptive drug to prevent the rapid loss of BMD that occurs when treatment is stopped [32].

\section{MECHANISM OF ACTION OF OSTEOPOROSIS THERAPIES}

The mechanism of action of osteoporosis therapies is summarized in Fig. 1. Nitrogen-containing (amino-) bisphosphonates (BPs) impair osteoclast function by inhibiting farnesyl pyrophosphate synthase (FPPS), thereby preventing the prenylation 


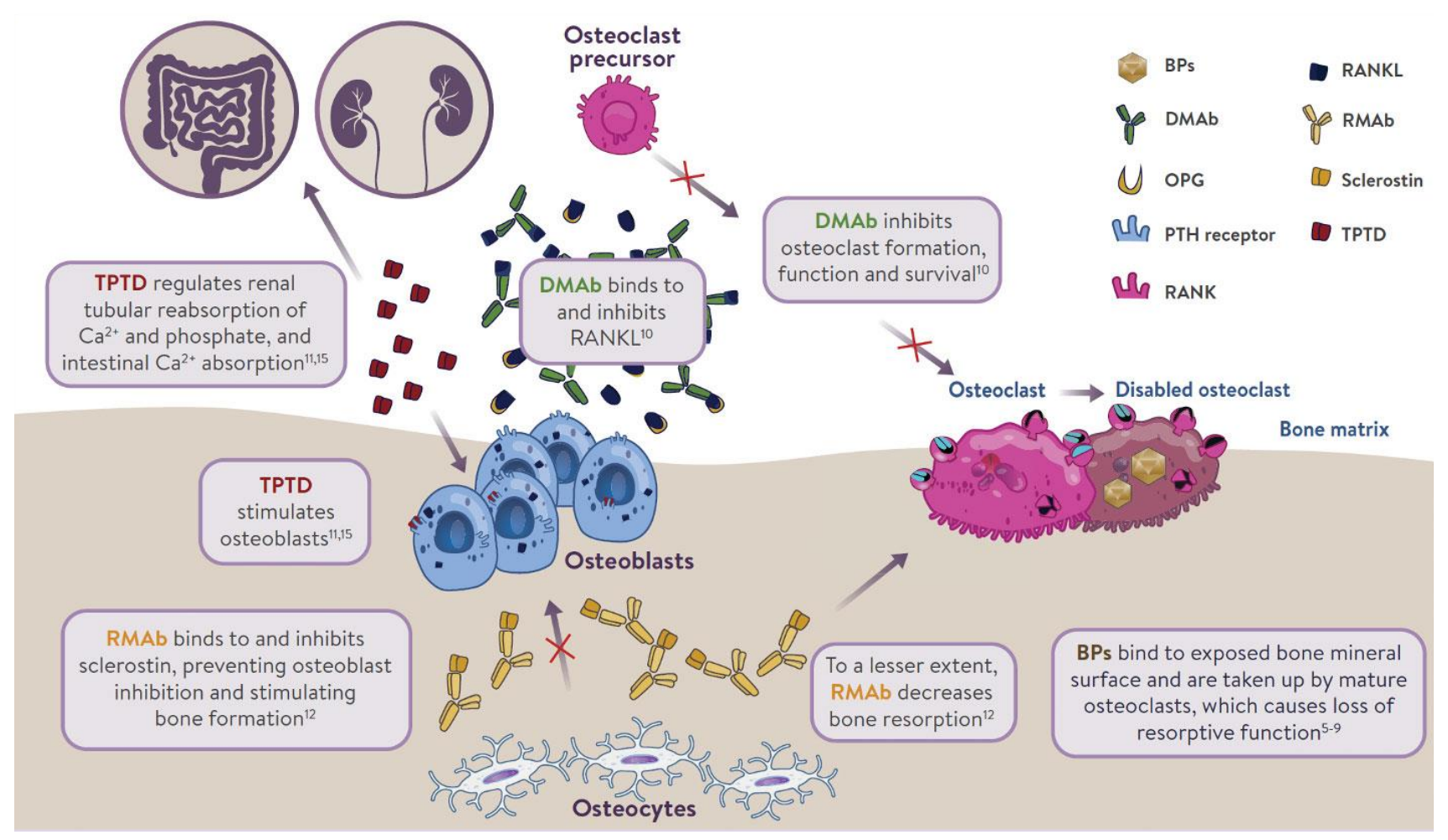

Fig. 1. Mechanism of action of osteoporosis therapies. BP, bisphosphonate; DMAb, denosumab; OPG, osteoprotegerin; PTH, parathyroid hormone; RANK, receptor activator of nuclear factor kappa-B; RANKL, receptor activator of nuclear factor kappa-B ligand; RMAb, romosozumab; TPTD, teriparatide.

of small GTPase proteins $[32,33]$. This results in disruption of cytoskeletal organization [34], loss of the ruffled membrane border [34], and altered vesicular trafficking [35]. In addition, while osteoclasts naturally undergo apoptosis, this process is accelerated in osteoclasts exposed to BPs [36]. BPs bind to bone mineral and are taken up by mature osteoclasts at sites of bone resorption [37]. BPs can remain bound to bone mineral for many years; those with greater binding affinities (zoledronic acid $>$ alendronate $>$ ibandronate $>$ risedronate) possess longer skeletal residency [38]. Consequently, after BP discontinuation, bound $\mathrm{BP}$ provides residual pharmacological action for many years $[38,39]$, in contrast to other anti-resorptive therapies in which activity is quickly lost after discontinuation (e.g., denosumab [DMAb], estrogen, raloxifene, and calcitonin) [40-42].

Although osteoblasts are not generally considered to be a target for BP inhibition, in vitro experiments provided direct evidence that inhibition of FPPS in osteoblasts may explain the blunting of the bone anabolic response to parathyroid hormone (PTH) observed after chronic exposure to BPs in rats [43]. BPs reduce prenylation of Rap1A, a small G protein participating in cytoskeletal reorganization in osteoblasts and allowing PTH to activate flat bone lining cells into cuboid, collagen-synthesizing osteoblasts [43]. Due to the inefficient uptake of BPs into osteoblasts by fluid-phase endocytosis [44], this mechanism is only observed after chronic treatment in vivo [43].

DMAb is a fully human monoclonal antibody that inhibits bone resorption by neutralizing with high affinity and specificity the receptor activator of nuclear factor- $\mathrm{kB}$ ligand (RANKL), a key mediator of osteoclast differentiation, function, and survival $[45,46]$. Unlike BPs, DMAb inhibits osteoclast activity at all developmental stages (prefusion, multinucleated, and resorbing mature osteoclasts) [37], leading to easier access to bone remodeling compartments in cortical bone than BPs [47]. DMAb is not incorporated into bone; therefore, its effect on bone resorption stops rapidly after treatment discontinuation [40].

TPTD, a recombinant human PTH, given subcutaneously once daily produces intermittent pulses of exogenous PTH, which stimulates bone remodeling (osteoblastic activity over osteoclastic activity). It also regulates reabsorption of calcium and phosphate in the kidney, and absorption of calcium in the intestine. Romosozumab inhibits sclerostin, a glycoprotein secreted by osteocytes. It acts as a modeling-based bone-forming 
agent with a dual effect on stimulating bone formation and, to a lesser extent, inhibiting bone resorption.

We will focus on long-term antiresorptive therapies because bone-forming therapies have a defined treatment duration ( 1 or 2 years). Once patients are diagnosed with osteoporosis, they will be at an increased risk for fracture for the rest of their lives. Even when patients' BMD improves because of treatment, they will still be at increased risk for fracture and their risk for fracture will eventually return to baseline if they stop treatment. This is similar to what occurs in patients with controlled diabetes or hypertension.

The appropriate duration of antiresorptive therapy (BPs or DMAb) has become a topic of discussion, due to concern about the possible treatment interruption risk of osteonecrosis of the jaw (ONJ) and atypical femur fracture (AFF), and "drug holidays" (treatment interruption), particularly from BPs, have become common practice.

\section{THE BENEFIT OF CONTINUOUS THERAPY OUTWEIGHS THE RARE RISKS}

The safety concerns of antiresorptives have been recently reviewed [33]. Observational register-based studies and post-marketing reports based upon millions of patient-years and long- term ( $>5$ years) clinical administration, have associated some previously-unknown, rare adverse events with antiresorptive use, including ONJ and subtrochanteric/diaphyseal AFFs [3436]. These rare risks should always be integrated in a global perspective taking into account the benefit of long-term pharmacological therapy of postmenopausal osteoporosis (Fig. 2) [48].

The International Task Force on Osteonecrosis of the Jaw defined ONJ as: (1) exposed bone in the maxillofacial region that does not heal within 8 weeks after identification by a health care provider; (2) exposure to an antiresorptive agent; and (3) no history of radiation therapy to the craniofacial region" [34]. In the osteoporosis patient population, who receive much lower doses of antiresorptives (BPs or DMAb), the incidence of ONJ is very low, ranging from $0.15 \%(150$ in 100,000$)$ to less than $0.001 \%$ (1 in 100,000 person-years of exposure), which appears to be only slightly higher than that seen in the general population [34]. In the Fracture REduction Evaluation of Denosumab in Osteoporosis Every 6 Months (FREEDOM) extension (DMAb $60 \mathrm{mg}$ subcutaneously every 6 months for up to 7 or 10 years in postmenopausal women with osteoporosis), 13 adjudicated cases of ONJ were reported, leading to an incidence of $0.05 \%$ (52 in 100,000 person-years of exposure) [37]. ONJ was slightly more common in women who had invasive oral procedures or events $(0.68 \%$ vs. $0.05 \%)$; however, the overall rate remained



Fig. 2. Putting the risks of osteoporotic fracture vs. rare adverse events into perspective. Adapted from Brown et al. [48]. DMAb-AFF, denosumab-associated atypical subtrochanteric and diaphyseal femur fracture; Bis-AFF, bisphosphonate-associated atypical subtrochanteric and diaphyseal femur fracture; DMAb-ONJ, denosumab-associated osteonecrosis of the jaw; Bis-ONJ, bisphosphonate-associated osteonecrosis of the jaw; MVA, motor vehicle accident; MOF, major osteoporotic fracture. ${ }^{\mathrm{a}} 10$-Year risk of major osteoporotic fracture by Canadian Fracture Risk Assessment Tool. 
low [38]. All cases of ONJ with complete follow-up resolved with treatment [38].

Factors associated with the development of ONJ include poor oral hygiene, glucocorticoid use, and invasive dental procedures such as dental extraction [34]. Therefore, it is suggested that patients should complete any invasive dental procedures before initiating an antiresorptive (BP or DMAb) to minimize the already small risk; however, those on treatment should not delay emergency dental procedures nor discount dental implants [34].

AFFs are insufficiency or fissure transverse fractures [39] originating on the lateral cortex of the subtrochanteric or diaphyseal (shaft) region of the femur and becoming oblique as they progress medially (medial spike) when complete $[35,36]$.

Concern has arisen that long-term BP use may increase the risk of these fractures through a number of putative mechanisms including a prolonged reduction of bone remodeling. Incidence rates of AFF range from 1.8 per 100,000 cases per year with a 2-year BP exposure to 113.1 per 100,000 cases per year with BP exposure from 8 to 9.9 years [36]. However, only 2 AFFs ( 8 per 100,000 person-years) were reported with the prolonged use of $\mathrm{DMAb}$ (up to 7 or 10 years), a more potent antiresorptive, in treatment-naïve postmenopausal women with osteoporosis: one in the long-term group during year 4 of the extension (year 7 of $\mathrm{DMAb}$ treatment) and one in the crossover group during year 3 of the extension (year 3 of DMAb treatment) [37]. In postmenopausal women with osteoporosis previously treated with oral BPs (alendronate for a mean duration of 6.2 to 6.4 years), AFF was adjudicated in one of 321 patients transitioning to zoledronic acid ( $5 \mathrm{mg}$, intravenous) and in two of 322 patients transitioning to DMAb over 1 year [40]. Transition to a more potent antiresorptive in patients previously treated with long-term BPs could prevent the clearance of accumulated BPs from the bone matrix and increase the risk of AFF. This possibility would have to be assessed in a much larger population transitioning from oral BPs to intravenous zoledronic acid or DMAb.

\section{INDIVIDUALIZED LONG-TERM PHARMACOLOGICAL THERAPIES}

Experts have proposed a "treat-to-target" strategy, in which a specific goal is set in order to achieve long-term fracture prevention (e.g., a total hip T-score between -2 and -1.5) [41] and therapy is individualized and periodically reassessed based on this goal [42]. Historically, BPs were the first-line treatment for osteoporosis, and physicians would consider another treatment after years of use or after a failure to respond. With treat-to-tar- get, physicians select the drug or sequence of drugs most likely to achieve the target over a given period, which could be short (1 to 2 years for imminent risk of fracture) or long (10 years for high risk of fracture) [43]. It is important to note that achieving this goal does not mean patients can stop therapy.

Through a meta-regression analysis of clinical trials of all pharmacological therapies commercially available, Bouxsein et al. [44] demonstrated that improvements in BMD were strongly associated with reductions in hip and vertebral fractures. This suggests that BMD can be used as a target and as a surrogate endpoint for fracture risk.

The Endocrine Society guidelines recommend postmenopausal women at high risk for fracture continue BP therapy without interruption, if they remain at high risk after 3 to 5 years of therapy, but also state that there is little evidence to support any recommendation regarding duration of therapy [28]. In a systematic literature review of patients who discontinued BPs, the risk of new clinical fracture was $20 \%$ to $40 \%$ higher and the risk of vertebral fracture was almost double compared to the period on BPs [45], indicating that "drug holidays" may not be safe in all patients on BPs. Despite a lack of long-term evidence, we should approach osteoporosis similarly to chronic conditions like hypertension and diabetes, which we are confident in treating long-term.

\section{Risedronate}

In the extension of the Vertebral Efficacy With Risedronate Therapy-MultiNational (VERT-MN) study, patients either received 7 years of risedronate $(n=31)$ or 5 years of placebo, followed by 2 years of risedronate $(n=30)$. Both groups were off therapy during year 8 . Bone turnover markers (BTMs) increased toward baseline, and total hip and femoral trochanter BMD decreased in both the 2- and 7-year risedronate groups; however, the risk of new vertebral fracture did not increase [46]. Given the small number of patients in each group, it is difficult to draw any conclusions from these results except that there is no residual effect on BMD after 1 year off therapy [46].

\section{Alendronate}

In Fracture Intervention Trial Long-term EXtension (FLEX; an extension of the FIT trial), postmenopausal women who received a mean of 5 years of alendronate daily either discontinued therapy $(n=428)$ or continued alendronate for a further 5 years $(n=643)$. Hip BMD gains plateaued after 3 years of alendronate treatment. Women who discontinued therapy showed a gradual decline in BMD and a gradual increase in BTMs, which 
approached baseline levels for hip BMD 5 years after stopping treatment [47]. There was a significantly lower risk of clinically recognized vertebral fractures in the group who continued alendronate ( $5.3 \%$ vs. $2.4 \%$; relative risk, $0.45 ; 95 \%$ confidence interval, 0.24 to 0.85 ). However, continuing alendronate did not offer additional protection against nonvertebral fractures [47].

\section{Zoledronic acid}

In the 6-year extension of Health Outcomes and Reduced Incidence with Zoledronic acid ONce Yearly-Pivotal Fracture Trial (HORIZON-PFT) [49], postmenopausal women were randomized after 3 years of zoledronic acid to continue therapy for another 3 years $(n=616)$ or switch to placebo $(n=617)$. In the group who continued zoledronic acid, femoral neck and hip BMD plateaued after the first 3 years and remained stable for the next 3 years. BTMs and BMD remained stable in the zoledronic acid group and trended toward pre-treatment levels in the placebo group. There was also a significant increase in new morphometric vertebral fractures in the placebo group (30 vs. $14, P=0.035$ ). However, continuing therapy did not offer additional protection against nonvertebral fractures [49]. This increase in fracture risk was not seen in the 9-year extension, where patients who received 6 years of zoledronic acid were randomized to continue therapy for 3 years $(n=95)$ or switch to placebo $(n=95)$, although the number of patients in the 9-year extension was much smaller [50].

In the HORIZON Recurrent Fracture Trial [51], zoledronic acid reduced the risk of death from any cause by $28 \%$ versus placebo $(P=0.01)$ in patients who started therapy within 90 days of a surgical repair of a hip fracture. This demonstrates a mortality benefit of actively treating osteoporosis.

After an initial increase in BMD with BPs, a plateau is reached after 2 to 3 years of treatment, particularly for hip and femoral neck BMD [47,50]. This may have contributed to the practice of BP "drug holidays," because physicians did not perceive an ongoing benefit. However, an ongoing improvement in spine BMD is observed with long-term use of alendronate [47] and zoledronic acid [49], which may explain the increase in vertebral fractures seen in patients who discontinued these treatments compared to those who did not. The American Society of Bone and Mineral Research Task Force proposed re-evaluating 10 -year fracture risk after 5 years of oral BPs or 3 years of intravenous BPs [52]. It should be noted that "re-evaluate" does not always mean "discontinue." High-risk patients require longterm therapy with either BPs or DMAb and studies have shown that women can safely transition from a BP to DMAb [53]. Phy- sicians can consider treatment interruption in patients who are not high-risk. These patients should be assessed every 2 to 4 years and therapy should be reinitiated if their fracture risk increases or after a maximum of 5 years off treatment, according to the Endocrine Society guidelines [54].

\section{Denosumab}

The effects of DMAb on bone resorption are rapidly reversible. When DMAb is discontinued after a short exposure (2 years), BTMs transiently increase from baseline, peaking approximately 12 months after the last dose (6 months after a planned dose is skipped), then decrease toward baseline [55]. BMD immediately decreases, reaching baseline approximately 18 months after the last dose [55]. Oral alendronate would preserve BMD gains when DMAb is discontinued after a short exposure [56]. When DMAb is discontinued after a longer exposure $(>4$ years), up-regulation of osteoclastogenesis is stronger, which may explain why BPs are not able to fully preserve BMD [57].

The FREEDOM study evaluated DMAb versus placebo for 3 years, followed by a 7-year extension study [37]. The investigators saw an increased rate of vertebral fracture after patients discontinued DMAb during FREEDOM or its extension, which was comparable to the level of vertebral fracture in patients on placebo [58]. There was a higher risk of multiple vertebral fractures in patients who discontinued DMAb (3.4\%) versus placebo $(2.2 \%)$, with the highest risk in those with a prior vertebral fracture before or during treatment [58]. Time off treatment and BMD loss off treatment were also weak predictors of multiple vertebral fractures [58]. These data underscore the need not to stop DMAb without considering alternative treatment at the 6-month dosing interval, in order to prevent a loss of vertebral fracture protection and BMD.

Unlike BPs, there is no plateau in spine, hip, or femoral neck $\mathrm{BMD}$, with continual gains observed during up to 10 years of treatment [37]. DMAb demonstrated a further reduction in nonvertebral fracture risk from years 4 to 10 , compared with the first 3 years [59]. This is the first treatment in osteoporosis to demonstrate a continuous increase in effectiveness over the long term. The yearly rate of new vertebral fractures (range, $0.90 \%$ to $1.86 \%$ ) and nonvertebral fractures (range, $0.84 \%$ to $2.55 \%$ ) in patients on DMAb remained low and was stable up to 10 years [37].

\section{CONCLUSIONS}

Antiresorptive drugs, such as amino-BPs and more recently, 
$\mathrm{DMAb}$, have dominated the landscape of osteoporosis therapies for the last three decades. Since osteoporosis is a chronic disease, anti-fracture therapy could conceivably continue for the rest of a patient's life. We discussed how best to use the pharmacological options available for postmenopausal osteoporosis to provide lifelong fracture protection in patients at high and very high risk of fracture. The benefit of osteoporosis therapies far outweighs the rare risks.

\section{CONFLICTS OF INTEREST}

Jacques P. Brown has received research support from Mereo BioPharma, Radius Health, and Servier; has served as a consultant for Amgen and Servier; and has served on speakers' bureaus for Amgen.

\section{ACKNOWLEDGMENTS}

The author wants to thank CPD Network Association (https:// www.cpdnetwork.org/) and MEDUCOM Health Inc., Healthcare Communications (https://www.meducom.ca), both located in Ontario, Canada for the conceptualization and production of figures used in this publication. The author also wants to thank Dr. Jonathan Adachi, McMaster University, Canada and Dr. Jeff Habert, University of Toronto, Canada, for their collaboration in a previous web-based medical education program addressing the long-term treatment of postmenopausal osteoporosis.

\section{ORCID}

Jacques P. Brown https://orcid.org/0000-0003-1910-788X

\section{REFERENCES}

1. NIH Consensus Development Panel on Osteoporosis Prevention, Diagnosis, and Therapy. Osteoporosis prevention, diagnosis, and therapy. JAMA 2001;285:785-95.

2. Bessette L, Ste-Marie LG, Jean S, Davison KS, Beaulieu M, Baranci $\mathrm{M}$, et al. The care gap in diagnosis and treatment of women with a fragility fracture. Osteoporos Int 2008;19:7986.

3. Adachi JD, Loannidis G, Berger C, Joseph L, Papaioannou A, Pickard L, et al. The influence of osteoporotic fractures on health-related quality of life in community-dwelling men and women across Canada. Osteoporos Int 2001;12:903-8.

4. Brenneman SK, Barrett-Connor E, Sajjan S, Markson LE,
Siris ES. Impact of recent fracture on health-related quality of life in postmenopausal women. J Bone Miner Res 2006; 21:809-16.

5. Brown JP, Adachi JD, Schemitsch E, Tarride JE, Brown V, Bell A, et al. Mortality in older adults following a fragility fracture: real-world retrospective matched-cohort study in Ontario. BMC Musculoskelet Disord 2021;22:105.

6. Tarride JE, Adachi JD, Brown JP, Schemitsch E, Slatkovska L, Burke N. Incremental costs of fragility fractures: a population-based matched-cohort study from Ontario, Canada. Osteoporos Int 2021 Feb 18 [Epub]. https://doi.org/10.1007/ s00198-021-05877-8.

7. Papaioannou A, Giangregorio L, Kvern B, Boulos P, Ioannidis G, Adachi JD. The osteoporosis care gap in Canada. BMC Musculoskelet Disord 2004;5:11.

8. Bell A, Hill MD, Herman RJ, Girard M, Cohen E; Canadian REduction of Atherothrombosis for Continued Health (REACH) Registry Steering Committee. Management of atherothrombotic risk factors in high-risk Canadian outpatients. Can J Cardiol 2009;25:345-51.

9. Eisman JA, Bogoch ER, Dell R, Harrington JT, McKinney RE Jr, McLellan A, et al. Making the first fracture the last fracture: ASBMR task force report on secondary fracture prevention. J Bone Miner Res 2012;27:2039-46.

10. Mitchell PJ. Best practices in secondary fracture prevention: fracture liaison services. Curr Osteoporos Rep 2013;11:52-60.

11. Hawley S, Javaid MK, Prieto-Alhambra D, Lippett J, Sheard S, Arden NK, et al. Clinical effectiveness of orthogeriatric and fracture liaison service models of care for hip fracture patients: population-based longitudinal study. Age Ageing 2016;45:236-42.

12. Metcalfe D, Zogg CK, Judge A, Perry DC, Gabbe B, Willett $\mathrm{K}$, et al. Pay for performance and hip fracture outcomes: an interrupted time series and difference-in-differences analysis in England and Scotland. Bone Joint J 2019;101-B:1015-23.

13. Gonzalez-Quevedo D, Bautista-Enrique D, Perez-Del-Rio V, Bravo-Bardaji M, Garcia-de-Quevedo D, Tamimi I. Fracture liaison service and mortality in elderly hip fracture patients: a prospective cohort study. Osteoporos Int 2020;31:77-84.

14. Binkley N, Blank RD, Leslie WD, Lewiecki EM, Eisman JA, Bilezikian JP. Osteoporosis in crisis: it's time to focus on fracture. J Bone Miner Res 2017;32:1391-4.

15. Leslie WD, Lix LM. Comparison between various fracture risk assessment tools. Osteoporos Int 2014;25:1-21.

16. Marques A, Ferreira RJ, Santos E, Loza E, Carmona L, da Silva JA. The accuracy of osteoporotic fracture risk predic- 
tion tools: a systematic review and meta-analysis. Ann Rheum Dis 2015;74:1958-67.

17. Burden AM, Tanaka Y, Xu L, Ha YC, McCloskey E, Cummings SR, et al. Osteoporosis case ascertainment strategies in European and Asian countries: a comparative review. Osteoporos Int 2021;32:817-29.

18. McCloskey E, Kanis JA, Johansson H, Harvey N, Oden A, Cooper A, et al. FRAX-based assessment and intervention thresholds: an exploration of thresholds in women aged 50 years and older in the UK. Osteoporos Int 2015;26:2091-9.

19. Compston J, Cooper A, Cooper C, Gittoes N, Gregson C, Harvey N, et al. UK clinical guideline for the prevention and treatment of osteoporosis. Arch Osteoporos 2017;12:43.

20. Giangregorio LM, Leslie WD; Manitoba Bone Density Program. Time since prior fracture is a risk modifier for 10-year osteoporotic fractures. J Bone Miner Res 2010;25:1400-5.

21. Johansson H, Siggeirsdottir K, Harvey NC, Oden A, Gudnason $\mathrm{V}, \mathrm{McCloskey} \mathrm{E}$, et al. Imminent risk of fracture after fracture. Osteoporos Int 2017;28:775-80.

22. Kanis JA, Hans D, Cooper C, Baim S, Bilezikian JP, Binkley N, et al. Interpretation and use of FRAX in clinical practice. Osteoporos Int 2011;22:2395-411.

23. Beaudoin C, Jean S, Moore L, Gamache P, Bessette L, SteMarie LG, et al. Number, location, and time since prior fracture as predictors of future fracture in the elderly from the general population. J Bone Miner Res 2018;33:1956-66.

24. Kanis JA, Johansson H, Harvey NC, Gudnason V, Sigurdsson G, Siggeirsdottir K, et al. Adjusting conventional FRAX estimates of fracture probability according to the recency of sentinel fractures. Osteoporos Int 2020;31:1817-28.

25. Kanis JA, Johansson H, Harvey NC, Gudnason V, Sigurdsson G, Siggeirsdottir K, et al. The use of 2-, 5-, and 10-year probabilities to characterize fracture risk after a recent sentinel fracture. Osteoporos Int 2021;32:47-54.

26. Kanis JA, Johansson H, Harvey NC, Lorentzon M, Liu E, Vandenput L, et al. An assessment of intervention thresholds for very high fracture risk applied to the NOGG guidelines: A report for the National Osteoporosis Guideline Group (NOGG). Osteoporos Int 2021 Apr 4 [Epub]. https://doi. org/10.1007/s00198-021-05942-2.

27. Kim HY, Jang EJ, Park B, Kim TY, Shin SA, Ha YC, et al. Development of a Korean Fracture Risk Score (KFRS) for predicting osteoporotic fracture risk: analysis of data from the Korean National Health Insurance Service. PLoS One 2016;11:e0158918.

28. Shoback D, Rosen CJ, Black DM, Cheung AM, Murad MH,
Eastell R. Pharmacological management of osteoporosis in postmenopausal women: an Endocrine Society guideline update. J Clin Endocrinol Metab 2020;105:dgaa048.

29. Kendler DL, Marin F, Zerbini CAF, Russo LA, Greenspan SL, Zikan V, et al. Effects of teriparatide and risedronate on new fractures in post-menopausal women with severe osteoporosis (VERO): a multicentre, double-blind, double-dummy, randomised controlled trial. Lancet 2018;391:230-40.

30. Saag KG, Petersen J, Brandi ML, Karaplis AC, Lorentzon $\mathrm{M}$, Thomas T, et al. Romosozumab or alendronate for fracture prevention in women with osteoporosis. N Engl J Med 2017;377:1417-27.

31. Cosman F, Nieves JW, Dempster DW. Treatment sequence matters: anabolic and antiresorptive therapy for osteoporosis. J Bone Miner Res 2017;32:198-202.

32. McClung MR. Role of bone-forming agents in the management of osteoporosis. Aging Clin Exp Res 2021;33:775-91.

33. Brown JP. Antiresorptives: safety concerns-clinical perspective. Toxicol Pathol 2017;45:859-63.

34. Khan AA, Morrison A, Hanley DA, Felsenberg D, McCauley LK, O'Ryan F, et al. Diagnosis and management of osteonecrosis of the jaw: a systematic review and international consensus. J Bone Miner Res 2015;30:3-23.

35. Shane E, Burr D, Ebeling PR, Abrahamsen B, Adler RA, Brown TD, et al. Atypical subtrochanteric and diaphyseal femoral fractures: report of a task force of the American Society for Bone and Mineral Research. J Bone Miner Res 2010; 25:2267-94.

36. Shane E, Burr D, Abrahamsen B, Adler RA, Brown TD, Cheung AM, et al. Atypical subtrochanteric and diaphyseal femoral fractures: second report of a task force of the American Society for Bone and Mineral Research. J Bone Miner Res 2014;29:1-23.

37. Bone HG, Wagman RB, Brandi ML, Brown JP, Chapurlat R, Cummings SR, et al. 10 Years of denosumab treatment in postmenopausal women with osteoporosis: results from the phase 3 randomised FREEDOM trial and open-label extension. Lancet Diabetes Endocrinol 2017;5:513-23.

38. Watts NB, Grbic JT, Binkley N, Papapoulos S, Butler PW, Yin $\mathrm{X}$, et al. Invasive oral procedures and events in postmenopausal women with osteoporosis treated with denosumab for up to 10 years. J Clin Endocrinol Metab 2019;104:2443-52.

39. Ng AC, Png MA, Mohan PC, Koh JS, Howe TS. Atypical femoral fractures: transverse morphology at lateral cortex is a critical feature. J Bone Miner Res 2014;29:639-43.

40. Miller PD, Pannacciulli N, Brown JP, Czerwinski E, Neder- 
gaard BS, Bolognese MA, et al. Denosumab or zoledronic acid in postmenopausal women with osteoporosis previously treated with oral bisphosphonates. J Clin Endocrinol Metab 2016;101:3163-70.

41. Ferrari S, Libanati C, Lin CJF, Brown JP, Cosman F, Czerwinski E, et al. Relationship between bone mineral density t-score and nonvertebral fracture risk over 10 years of denosumab treatment. J Bone Miner Res 2019;34:1033-40.

42. Cummings SR, Cosman F, Lewiecki EM, Schousboe JT, Bauer DC, Black DM, et al. Goal-directed treatment for osteoporosis: a progress report from the ASBMR-NOF working group on goal-directed treatment for osteoporosis. J Bone Miner Res 2017;32:3-10.

43. Lewiecki EM. Osteoporosis: treat-to-target. Curr Osteoporos Rep 2017;15:103-9.

44. Bouxsein ML, Eastell R, Lui LY, Wu LA, de Papp AE, Grauer A, et al. Change in bone density and reduction in fracture risk: a meta-regression of published trials. J Bone Miner Res 2019;34:632-42.

45. Dennison EM, Cooper C, Kanis JA, Bruyere O, Silverman S, McCloskey E, et al. Fracture risk following intermission of osteoporosis therapy. Osteoporos Int 2019;30:1733-43.

46. Eastell R, Hannon RA, Wenderoth D, Rodriguez-Moreno J, Sawicki A. Effect of stopping risedronate after long-term treatment on bone turnover. J Clin Endocrinol Metab 2011; 96:3367-73.

47. Black DM, Schwartz AV, Ensrud KE, Cauley JA, Levis S, Quandt SA, et al. Effects of continuing or stopping alendronate after 5 years of treatment: the Fracture Intervention Trial Long-term Extension (FLEX): a randomized trial. JAMA 2006;296:2927-38.

48. Brown JP, Morin S, Leslie W, Papaioannou A, Cheung AM, Davison KS, et al. Bisphosphonates for treatment of osteoporosis: expected benefits, potential harms, and drug holidays. Can Fam Physician 2014;60:324-33.

49. Black DM, Reid IR, Boonen S, Bucci-Rechtweg C, Cauley JA, Cosman F, et al. The effect of 3 versus 6 years of zoledronic acid treatment of osteoporosis: a randomized extension to the HORIZON-Pivotal Fracture Trial (PFT). J Bone Miner Res 2012;27:243-54.

50. Black DM, Reid IR, Cauley JA, Cosman F, Leung PC, Lakatos $\mathrm{P}$, et al. The effect of 6 versus 9 years of zoledronic acid treatment in osteoporosis: a randomized second exten- sion to the HORIZON-Pivotal Fracture Trial (PFT). J Bone Miner Res 2015;30:934-44.

51. Lyles KW, Colon-Emeric CS, Magaziner JS, Adachi JD, Pieper CF, Mautalen C, et al. Zoledronic acid and clinical fractures and mortality after hip fracture. N Engl J Med 2007; 357:1799-809.

52. Adler RA, El-Hajj Fuleihan G, Bauer DC, Camacho PM, Clarke BL, Clines GA, et al. Managing osteoporosis in patients on long-term bisphosphonate treatment: report of a task force of the American Society for Bone and Mineral Research. J Bone Miner Res 2016;31:16-35.

53. Miller PD, Pannacciulli N, Malouf-Sierra J, Singer A, Czerwinski E, Bone HG, et al. Efficacy and safety of denosumab vs. bisphosphonates in postmenopausal women previously treated with oral bisphosphonates. Osteoporos Int 2020;31: 181-91.

54. Eastell R, Rosen CJ, Black DM, Cheung AM, Murad MH, Shoback D. Pharmacological management of osteoporosis in postmenopausal women: an Endocrine Society clinical practice guideline. J Clin Endocrinol Metab 2019;104:1595622.

55. Bone HG, Bolognese MA, Yuen CK, Kendler DL, Miller PD, Yang YC, et al. Effects of denosumab treatment and discontinuation on bone mineral density and bone turnover markers in postmenopausal women with low bone mass. J Clin Endocrinol Metab 2011;96:972-80.

56. Freemantle N, Satram-Hoang S, Tang ET, Kaur P, Macarios D, Siddhanti S, et al. Final results of the DAPS (Denosumab Adherence Preference Satisfaction) study: a 24-month, randomized, crossover comparison with alendronate in postmenopausal women. Osteoporos Int 2012;23:317-26.

57. Solling AS, Harslof T, Langdahl B. Treatment with zoledronate subsequent to denosumab in osteoporosis: a randomized trial. J Bone Miner Res 2020;35:1858-70.

58. Cummings SR, Ferrari S, Eastell R, Gilchrist N, Jensen JB, McClung $\mathrm{M}$, et al. Vertebral fractures after discontinuation of denosumab: a post hoc analysis of the randomized placebo-controlled FREEDOM trial and its extension. J Bone Miner Res 2018;33:190-8.

59. Ferrari S, Butler PW, Kendler DL, Miller PD, Roux C, Wang AT, et al. Further nonvertebral fracture reduction beyond 3 years for up to 10 years of denosumab treatment. J Clin Endocrinol Metab 2019;104:3450-61. 